\title{
CONCURRENT INBREEDING AND SELECTION IN THE DOMESTIC FOWL
}

\author{
FRED T. SHULTZ \\ Division of Poultry Husbandry, University of California, Berkeley \\ Received 26.vii.52
}

Heterosis has played a vital part in improving agricultural products. Long utilised to particular advantage in corn (review by Sprague, I946), heterosis is becoming of increasing importance in certain other plants (Ashton, 1946), swine (Dickerson, Lush and Culbertson, 1946), and poultry meat (Jull, I 952). More recently, its use for egg production has been studied in the chicken (Warren, 1950; Bell et al., I952).

Despite the number of inbreeding and crossing experiments reported, the genetic mechanism responsible for heterosis and the origin of this mechanism by natural selection during the course of evolution is not understood. Selection experiments such as those of Mather and Harrison (1949) and Lerner and Dempster (I95I), investigations of natural populations by Dobzhansky (1947, 1950) and others, and detailed studies of such polygenic traits as extra venation in Drosophila by Dubinin (1948) and crooked toes in chickens by Hicks (unpub.) have helped us. The majority of such studies, however, do not consider all of the three primary forces acting on domestic animals and plants ; viz. natural selection, artificial selection, and inbreeding.

The present paper deals with the first phase of an experiment on the effects of concomitant inbreeding and selection in the chicken, permitting to make some inferences as to the nature of the genetic system and the forces involved in its maintenance or deterioration.

\section{CHARACTERS STUDIED}

The characters analysed are (I) those which served as the criterion of selection, and (2) others for which the nature of response to inbreeding and indirect selective forces was studied.

Characters selected directly :-

(a) November egg weight. Mean weight of all eggs laid during November of the first year of lay.

(b) November egg number. Total number of eggs laid during November of the first year of lay.

(c) November egg mass. Product of November egg number and November egg weight. In each line direct selection was applied to only one component, either egg number or egg weight, but not both. 
Other characters :-

(d) Spring egg weight. Mean weight of all eggs laid in a five-day period at the beginning of each of the months of March and April. In I95I, the mean weight of five eggs laid in April was used.

(e) Six weeks body weight.

$(f)$ December body weight. Adult body weight (approximately at $8 \frac{1}{2}$ months of age).

(g) Shank length. Length of the shank measured in December.

The heritability of November and April egg weight in the production-bred flock has been estimated by Lerner and Cruden (I95I) at approximately $0 \cdot 60$. November egg number has not been analysed in detail in the production-bred flock, but studies on other measurements of egg number (Lerner and Hazel, I947; Lerner, Cruden, and Taylor, 1949) indicate that it should respond to mass selection.

The relationship between the two primary criteria of selection, November egg number and egg weight, is not well known. Rate of lay and egg size for the November to February were negatively correlated in a study by Taylor and Lerner (1938), while Blyth (1952) found such a negative correlation exists only at higher levels of laying (based on March production of Brown Leghorns).

Egg weight and body size in general are closely correlated. The genetic and phenotypic correlations between November and April egg weight were found to be 0.91 and 0.65 respectively (Lerner and Cruden, 195I). The same authors found a phenotypic correlation of 0.539 between December body weight and November egg weight. Two genetic correlations were given, 0.456 based on combined sire and dam components and $0.94 \mathrm{I}$ based on the sire component alone. A maternal effect on December body weight of o. I5 was found indicating that the genetic correlation based on the combined sire and dam components may be subject to error. The relationships between November egg weight and shank length has not been specifically studied. Lerner (1946) found that the phenotypic correlations of shank length with beginning egg weight (mean weight of the first Io eggs laid) and January egg weight were 0.29 and 0.30 respectively, while the phenotypic correlation between shank length and December body weight was 0.52 .

\section{EXPERIMENTAL DESIGN AND MATERIALS}

Eight inbred lines of chickens were established from the 1944 generation of the University of California production-bred flock (Lerner, I950). Artificial selection was practiced for a single character in each line. The respective characters under selection in the lines were as follows :- 


\begin{tabular}{|c|c|c|}
\hline Line & Character selected & Direction \\
\hline HNP & November egg number & High \\
\hline HNM & :" & High \\
\hline LNP & " & Low \\
\hline LNM & $\eta$ & Low \\
\hline HWP & November egg weight & High \\
\hline HWM & , & High \\
\hline LWP & , & Low \\
\hline LWM & , & Low \\
\hline
\end{tabular}

When speaking of a pair of lines selected for the same character in the same direction (or of reciprocal crosses between two such lines) only the first two letters will be used ; e.g. the symbol HN includes HNP and HNM. Full designation of the parental lines will be given when referring to a single cross, the sire's line being given first.

Pullets were selected on the basis of their own record, with occasional consideration given to sister performance. Since dams, selected on the basis of their daughters' records were occasionally used, the average inter-generation span was somewhat higher than one year. Only year-old sires, selected on the basis of their sisters' records, were used.

A considerable reduction of selection pressure occurred in the latter part of the experiment. The number of offspring per dam surviving until breeding age decreased as inbreeding increased (Düzgünes, 1950) necessitating selection of a larger proportion of the available population. Furthermore, disease outbreaks occurred in the fall of 1949 and $195^{\circ}$ (Lerner, Taylor and Beach, 1950; and unpublished) which seriously affected November egg number and to some extent November egg weight. The disease in 1949 also lowered hatchability of affected birds in later mating seasons, further reducing the number of offspring in the succeeding generation. These factors led to the ultimate extinction of one line (LWM).

Rapid increases in the computed coefficients of inbreeding were obtained by restricting the size of the breeding population within each line to a single sire mated to several dams. Twelve to fourteen females per line were used as dams for each of the first four generations after which the number was reduced to six to eight females to permit making crosses. The numbers of pullet offspring and their mean coefficients of inbreeding in each line are given in table $\mathrm{I}$.

The production-bred flock (Lerner, 1950) served as a non-inbred control. Selection for various egg production characters, chiefly high hen-housed average egg-number (production index) for the first year of lay and high spring egg weight, was practiced in this flock (Lerner and Dempster, I951).

Within the inbreeding experiment the lines selected for egg number served as inbred controls for egg weight. Similarly, the lines selected for egg weight served as inbred controls for egg number. Because of correlated changes in these two characters, the controls are not entirely independent of the experimental lines. 
Reciprocal crosses between lines selected for the same character in the same direction were made in each of the last three years of the experiment (I949-5I) except for $\mathrm{LWP} \times \mathrm{LWM}$ in I95I, omitted because of lack of LWM females. In I95I, additional crosses were made between lines selected for the same character but in opposite directions $(\mathrm{HN} \times \mathrm{LN}$ and $\mathrm{HW} \times \mathrm{LW})$ and between lines selected for different characters but in the same direction $(\mathrm{HN} \times \mathrm{HW}$ and $\mathrm{LN} \times \mathbf{L W})$.

TABLE I

Computed inbreeding coefficients $(F)$ of birds alive rst December of year of hatch

\begin{tabular}{|c|c|c|c|c|c|c|c|c|c|c|c|c|c|c|}
\hline \multirow{3}{*}{ Line } & \multicolumn{14}{|c|}{ Year of hatch } \\
\hline & \multicolumn{2}{|c|}{1945} & \multicolumn{2}{|c|}{1946} & \multicolumn{2}{|c|}{1947} & \multicolumn{2}{|c|}{$194^{8}$} & \multicolumn{2}{|c|}{1949} & \multicolumn{2}{|c|}{$195^{\circ}$} & \multicolumn{2}{|c|}{1951} \\
\hline & No. & $\mathbf{F}$ & No. & $\mathrm{F}$ & No. & F & No. & $\mathbf{F}$ & No. & $\mathbf{F}$ & No. & $\mathbf{F}$ & No. & $\mathbf{F}$ \\
\hline HNP & 73 & 0 & 44 & ${ }_{17} \cdot 6$ & 52 & $33 \cdot 2$ & 24 & 42.4 & 31 & $49 \cdot I$ & 9 & $47 \cdot 3$ & & \\
\hline HNM & 85 & 0 & 16 & $18 \cdot 0$ & 65 & $35 \cdot 6$ & 21 & 44.7 & $\begin{array}{l}32 \\
42\end{array}$ & $\begin{array}{l}49 . \\
52.3\end{array}$ & 22 & $\begin{array}{l}47.3 \\
57.5\end{array}$ & 8 & $\begin{array}{l}35.9 \\
62 \cdot 4\end{array}$ \\
\hline LNP & 54 & 0.2 & 50 & $18 \cdot 7$ & 53 & $30 \cdot 0$ & 11 & $3_{36}^{7} \cdot 0$ & 42 & $38^{\circ} \cdot 4$ & 44 & $39 \cdot 0$ & 28 & $48 \cdot 6$ \\
\hline LNM & 25 & 0 & 32 & $12 \cdot 5$ & 25 & $26 \cdot 0$ & 24 & $35 \cdot 2$ & 23 & 43.5 & 37 & $48 \cdot 4$ & 9 & $52 \cdot 9$ \\
\hline HWP & 53 & 0.5 & 76 & 15.7 & 37 & $24 \cdot 3$ & 52 & $23 \cdot 2$ & 34 & $32 \cdot 0$ & 15 & $33 \cdot 3$ & 20 & $4^{r} \cdot 4$ \\
\hline HWM & 46 & 0 & 34 & 13.9 & $\begin{array}{l}19 \\
19\end{array}$ & 27.8 & 19 & 36.8 & $\begin{array}{l}15 \\
15\end{array}$ & $39 \cdot 8$ & 18 & $48 \cdot 0$ & 10 & 52.7 \\
\hline LWP & 56 & $3: 5$ & 34 & $I I \cdot 2$ & 29 & $27 \cdot 3$ & 24 & 33.4 & 17 & $47 \cdot 6$ & 31 & $49^{\circ} 0$ & II & $5^{8 \cdot 1}$ \\
\hline LWM & $6 x$ & 0 & $6 i$ & 17.5 & 70 & $26 \cdot 9$ & 15 & 38.7 & 13 & 43.0 & 3 & $40 \cdot 3$ & o & $\cdots$ \\
\hline Mean & 453 & 0.52 & 347 & 15.88 & $35^{\circ}$ & $28 \cdot 92$ & 190 & $34 \times 3$ & 217 & $43 \cdot 25$ & 179 & $45 \cdot 8 z$ & 95 & $50 \cdot 88$ \\
\hline
\end{tabular}

Grosses were made by placing three to six females of one line in the mating pen with the male of the other line. Hence the same sire was used for propagation of his own inbred line and in crosses of that line with other inbred lines. A maximum of 14 dams was mated to one sire, six to eight of which were from his line and the remainder from other lines.

\section{RESULTS}

Only the results of November egg weight and number and December body weight in graphic form are presented here. The complete data on all characters studied are given in both tabular and graphic form in copies of the dissertation deposited in the library of the University of California at Berkeley.

November egg weight.-The effects of simultaneous selection and inbreeding on November egg weight are shown in fig. $\mathrm{I}$. There are six points that may be particularly noted.

First, rapid responses to selection in the four lines selected for high or low November egg weight were obtained during the early generations. Thus, in the third generation, the difference between 
the means of the high and low lines was $12 \cdot 2 \mathrm{gm}$. In the succeeding four generations no further response was observable in the HW lines. The LW lines, except for the brief period of plateau around the third generation, continued to decline an additional $3 \mathrm{gm}$. In the lines selected for November egg number, a correlated response of egg weight has occurred as expected from the negative correlation mentioned earlier. The difference between the means of the LN and $\mathrm{HN}$ lines was negligible during the first three generations and increased to only $2 \cdot 2 \mathrm{gm}$. in the seventh generation (I95I), in contrast to a difference of approximately $15 \mathrm{gm}$. between the HW and LW lines.

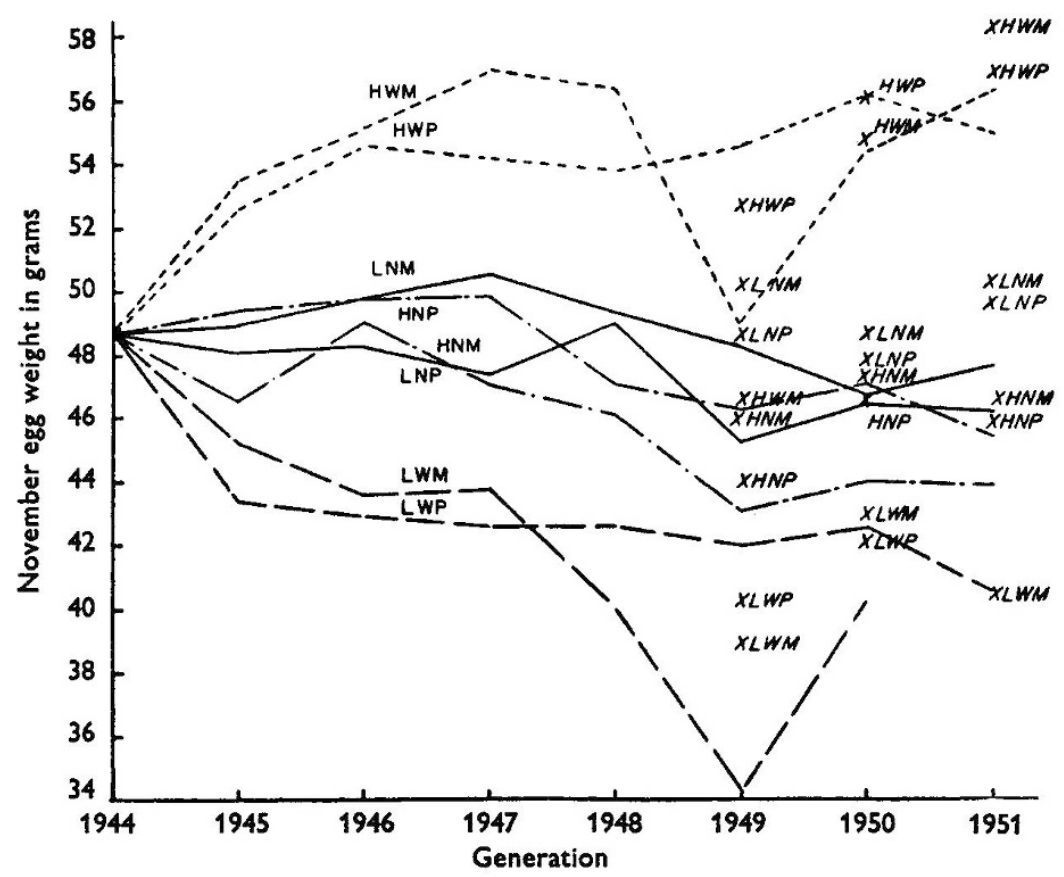

Fig. 1.-November egg weight in eight inbred lines and their crosses. Positions of crosses are marked by an $\mathrm{X}$ followed by designation of sire's line (dams are from the other line selected in the same manner as the sire's line). The LWM line was lost in $195^{\circ}$ from poor reproductivity.

Second, the means of the inbred controls (i.e. the four lines selected for egg number) have decreased in the later generations of the experiment. The mean November egg weight of the 1944 generation of the production-bred flock was $48 \cdot 6 \mathrm{gm}$. During the first three generations the inbred control lines fluctuated around this value with a mean for the three years of $48 \cdot 7 \mathrm{gm}$. In subsequent generations, a general decrease approximately equal in magnitude to that observed in the LW lines occurred.

Third, genetic homeostasis (Lerner, I950) appears to be manifested. Lerner and Dempster (195I) failed to find evidence of any negative correlation between April egg weight and reproductive fitness in the 
production-bred flock. However, selection for egg size in the production-bred flock was for an intermediate weight (Lerner, I95I) whereas the extreme deviates were selected in these lines. In the HW lines in the early generations the mean of dams weighted for the number of offspring produced was $0.074 \mathrm{gm}$. less than the unweighted mean of dams (table 2). Thus, dams laying smaller eggs

TABLE 2

Weighted (for number of offspring alive Ist Decembcr) minus unwcighted means of dams for November egg weight

\begin{tabular}{|c|c|c|c|c|c|c|}
\hline \multirow{2}{*}{$\begin{array}{l}\text { Pooled } \\
\text { lines }\end{array}$} & \multicolumn{3}{|c|}{$1944^{-1} 946$} & \multicolumn{3}{|c|}{$1947-195^{\circ}$} \\
\hline & $\begin{array}{l}\text { No. of } \\
\text { dams }\end{array}$ & $\begin{array}{l}\text { No. of } \\
\text { offspring }\end{array}$ & Difference & $\begin{array}{l}\text { No. of } \\
\text { dams }\end{array}$ & $\begin{array}{c}\text { No. of } \\
\text { offspring }\end{array}$ & Differences \\
\hline $\begin{array}{l}\text { HW } \\
\text { LN } \\
\text { HN } \\
\text { LW }\end{array}$ & $\begin{array}{l}64 \\
62 \\
67 \\
69\end{array}$ & $\begin{array}{l}219 \\
215 \\
334 \\
292\end{array}$ & $\begin{array}{r}-0.074 \\
0.33^{8} \\
0 \cdot 14^{0} \\
0.104\end{array}$ & $\begin{array}{l}48 \\
37 \\
47 \\
44\end{array}$ & $\begin{array}{r}129 \\
53 \\
121 \\
76\end{array}$ & $\begin{array}{r}-0.288 \\
o \cdot 392 \\
o \cdot 132 \\
0.459\end{array}$ \\
\hline
\end{tabular}

tended to reproduce themselves only slightly better than those laying larger eggs. In the later generations, however, the difference was 0.288 . In the LW lines, dams with higher egg weight tended to reproduce better, this tendency likewise becoming much stronger in the later generations, the differential increasing from $0 \cdot 104$ to 0.459 . In $\mathrm{HN}$ and LN lines, dams with higher egg weights tended to reproduce themselves better throughout the experiment.

Fourth, the genetic variance, obtained from half and full sister correlations, although fluctuating considerably from year to year because of the small numbers involved, does not seem to have decreased as inbreeding continued (table 3 ).

TABLE 3

Genetic variance and heritability estimates for November egg weight

\begin{tabular}{|c|c|c|c|c|}
\hline \multirow{2}{*}{ Lines } & \multicolumn{2}{|c|}{ Genetic variance } & \multicolumn{2}{|c|}{ Heritability } \\
\hline & 1945 and 1946 & $194^{8}$ and $195^{\circ}$ & 1945 and 1946 & 1948 and 1950 \\
\hline $\begin{array}{l}\text { HW } \\
\text { LN } \\
\text { HN } \\
\text { LW }\end{array}$ & $\begin{array}{l}1 \cdot 9840 \\
8 \cdot 9516 \\
0.8192 \\
4 \cdot 1744\end{array}$ & $\begin{array}{r}2 \cdot 7444 \\
(-11 \cdot 0336) \\
8 \cdot 754^{8} \\
7 \cdot 1200\end{array}$ & $\begin{array}{l}0.242 \\
0.650 \\
0.095 \\
0.471\end{array}$ & $\begin{array}{c}0.225 \\
-0.550) \\
0.954 \\
0.787\end{array}$ \\
\hline
\end{tabular}

Fifth, the crosses occur in the relative order that would be expected from the assumption that gains from selection acting directly on egg weight, or indirectly as a result of the negative correlation between egg weight and egg number, have been realised in all lines. Thus 
in all three generations in which crosses were made (1949-5I) crosses between the HW lines were highest for egg weight followed in descending order by LN, HN, and LW. Furthermore, the additional types of crosses performed in $195^{1}$ lie in the order expected on the basis of the above assumption (fig. 2).

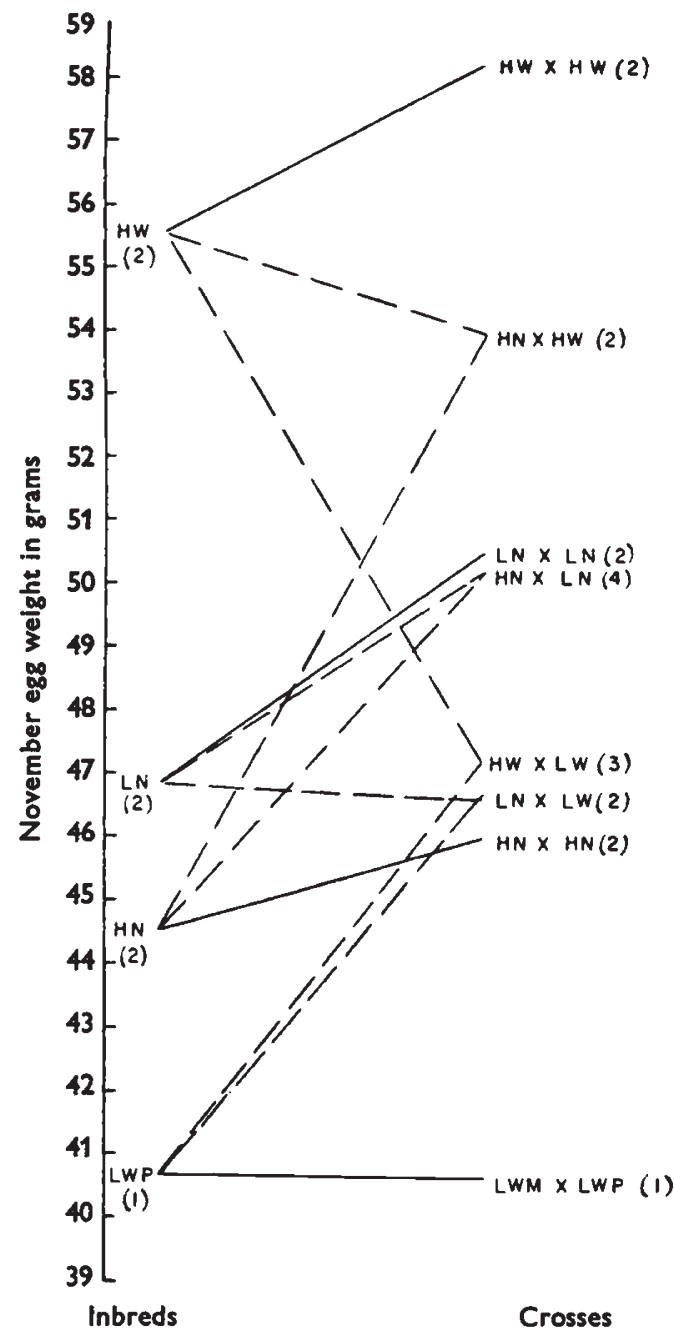

FIG. 2.--Relative values of inbreds and crosses of $195^{1}$ generation for November egg weight. The connecting lines between inbreds and crosses are drawn merely to facilitate interpretations. The numbers in parentheses represent the number of lines or line crosses (including reciprocal line crosses) pooled.

Sixth, means of crosses between lines selected for the same character in the same direction frequently are greater than the means of the parental inbred lines. In 1951 , the year in which no disease outbreaks were experienced, the difference between inbreds and crosses was greatest for HW and LN. The HN crosses were only slightly superior 
to the HN inbreds, whereas the LWM $\times L W P$ cross and LWP inbreds were approximately equal (there were no $L W P \times L W M$ crosses or LWM inbreds in this year).

November egg number (fig. 3). Severe inbreeding depression of roughly 12 eggs occurred in the second and third generations (1946 and 1947). Thereafter little or no change was evident.

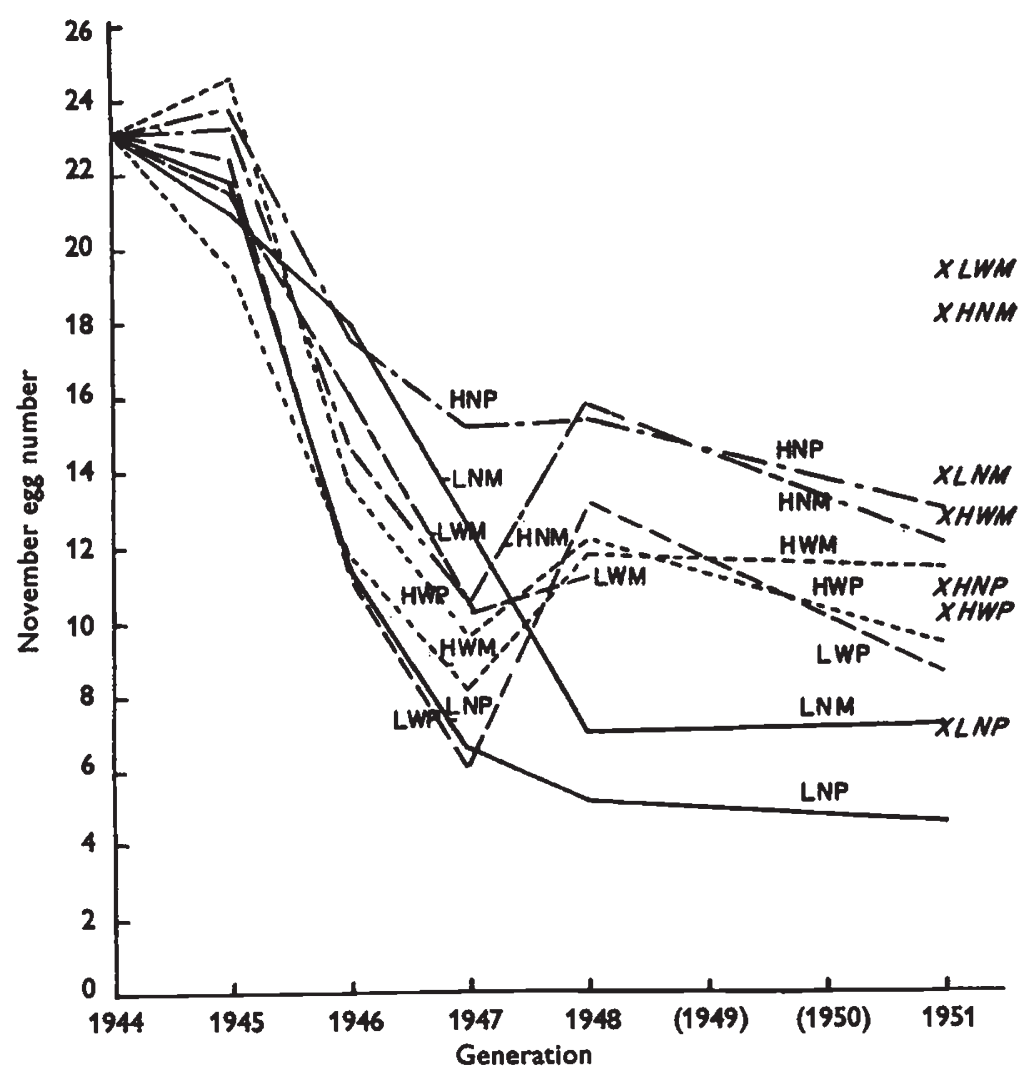

Fig. 3. - November egg number. No records were available in 1949 and 1950 because of disease. For description see fig. $r$.

The effects of selection did not reveal themselves until the fourth generation when the HN lines finally became clearly differentiated from the LN lines with the HW and LW lines lying intermediate. Selection for egg weight did not result in differentiation between the LW and HW lines for egg number.

The crosses (figs. 3 and 4) are not as uniform for egg number as they were for egg weight. However, the means of the reciprocal crosses $\mathrm{HN} \times \mathrm{HN}, \mathrm{HW} \times \mathrm{HW}$, and $\mathrm{LN} \times \mathrm{LN}$, are arranged in that order, although the order of the individual crosses is mingled. The single cross involving the $\mathrm{LW}$ lines $(\mathrm{LWM} \times \mathrm{LWP})$ was exceptionally high.

Crosses between lines selected differently do not lie in the order 
observed for egg weight. They generally exceeded the crosses between lines selected similarly (fig. 4). Thus the unweighted mean was I5.8I eggs for crosses between lines selected for the same character but in opposite directions, $14^{\circ}$. I for crosses between lines selected for different characters, and only 13.23 for crosses between lines selected for the same character in the same direction.

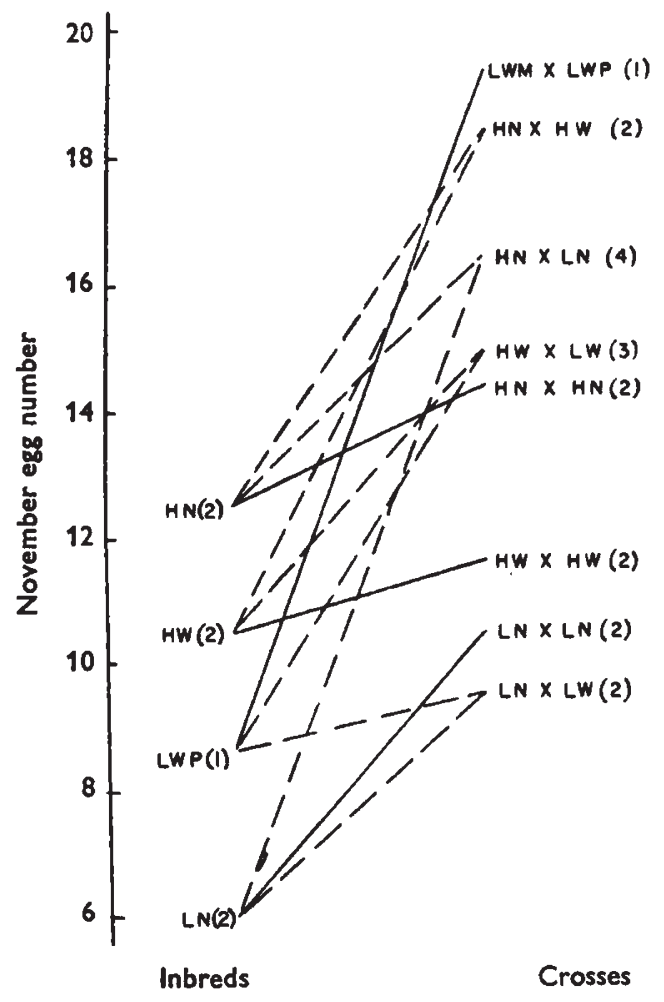

FIg. 4.-Relative values of inbreds and crosses of $195^{1}$ generation for November egg number. The connecting lines between inbreds and crosses are drawn merely to facilitate interpretations. The numbers in parentheses represent the number of lines or line crosses (including reciprocal line crosses) pooled.

In general, crosses tend to be superior to both parental lines, the exception being $\mathrm{HWP} \times \mathrm{HWM}$ which was intermediate and $\mathrm{HNP} \times \mathrm{HNM}$ and LNM $\times$ LWP which were lower than either parental line. The first two exceptions were crosses between similarly selected lines, the third being between lines selected for different characters.

The mean of all crosses is more than four eggs lower than the mean of the I95I production-bred flock. Only one cross, LWM $\times$ HWM, exceeded the mean of the production-bred flockby $0 \cdot 2$ of an egg.

November egg mass.-Results for egg mass were very similar to those for egg number. This is expected because changes in egg number contribute more to variation in egg mass than do changes in 
egg weight. The only notable exception is that the HW lines and line crosses have higher values for egg mass than the $\mathrm{HN}$ lines in contrast to lower values for egg number.

Spring egg weight.-The results for spring egg weight were almost identical with those for November egg weight. Indirect selection

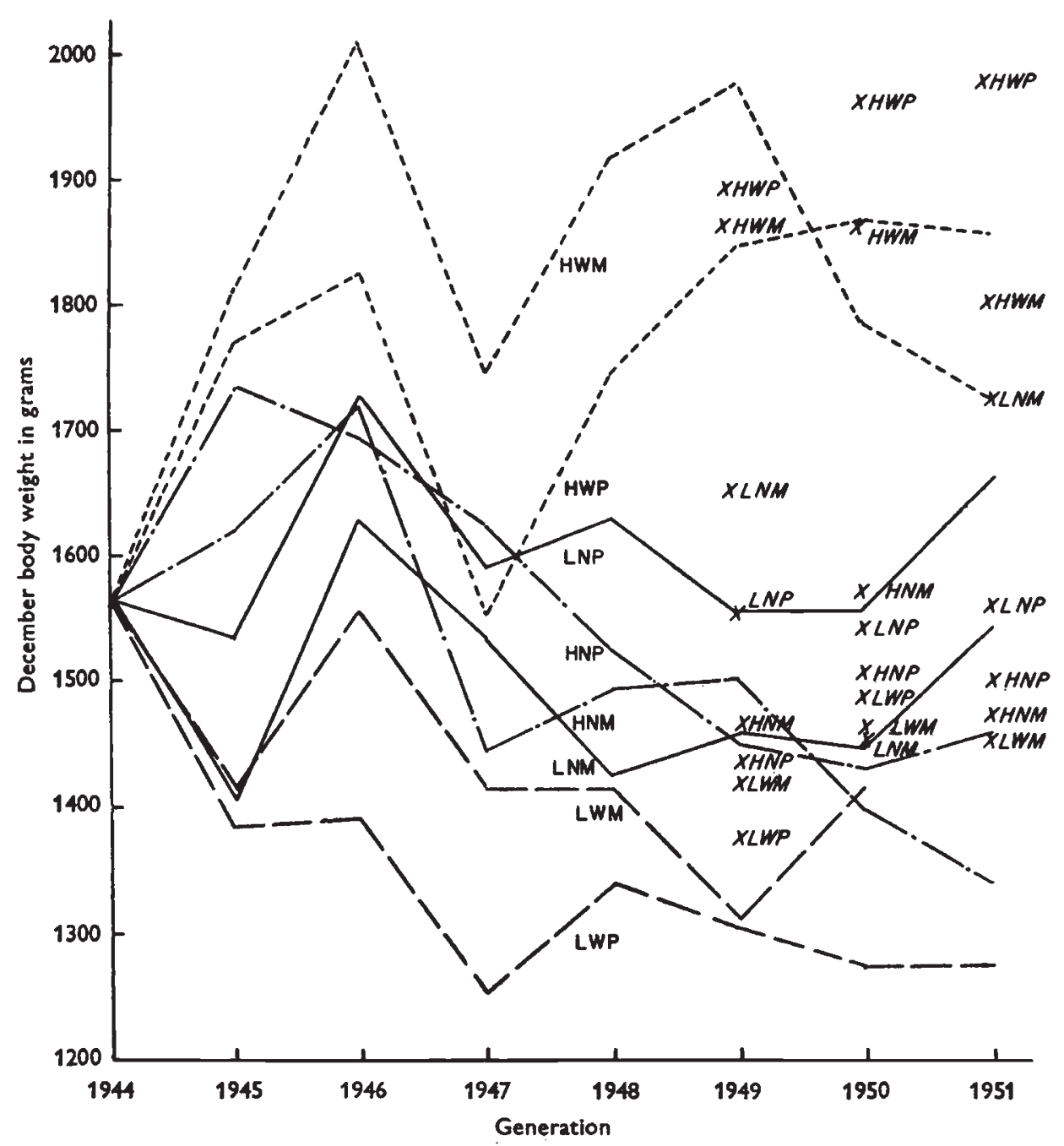

FIG. 5.-December body weight. For description see fig. I.

was effective as expected in view of the genetic correlation between the two measures of egg weight. During the early generations the LN lines remained at approximately the level of the 1944 generation of the production-bred flock, the $\mathrm{HN}$ lines approximately $2 \mathrm{gm}$. lower. As in November egg weight, a decline occurred in the LN and $\mathrm{HN}$ lines in the later generations.

The failure of the crosses between lines selected (directly or 
indirectly) for low egg weight to exceed the inbreds was even more striking for spring egg weight than for November egg weight in $195 \mathrm{I}$. Thus the mean of HN crosses $(47.9)$ was actually lower than the mean of the inbreds $(48 \cdot 3)$. The LWM $\times$ LWP was about equal the mean of the LWP inbreds in I95I and the last known value (I950) for the LWM line.

December body weight (fig. 5).-The production-bred flock showed a large and consistent increase during the years 1944 to 1948 (from

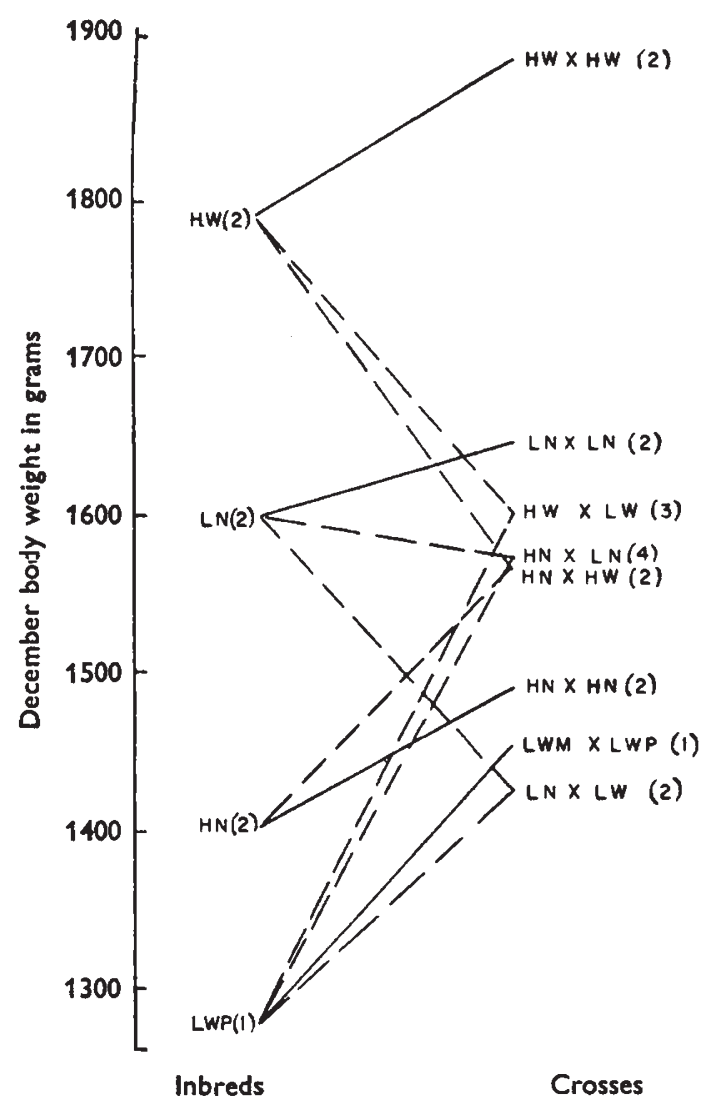

FIG. 6.--Relative values of inbreds and crosses of 1951 generation for December body weight (females only). The connecting lines between inbreds and crosses are drawn merely to facilitate interpretations. The numbers in parentheses represent the number of lines or line crosses (including reciprocal line crosses) pooled.

I563 to $18 \mathrm{I} 4 \mathrm{gm}$.) thereafter remaining relatively stable. Since body weight was not a criterion of selection, this rise is presumably a correlated response to selection for higher egg weight which was particularly intensified about $\mathbf{1} 946$.

The effect of selection in the HW and LW lines closely parallels that observed for November egg weight. Virtually all of the response to selection in the HW lines was obtained in the first generation. Thereafter, body weight fluctuated around the same level later 
attained by the production-bred flock. The LN lines showed a variable behaviour, LNP remaining relatively stable at a level slightly above the 1944 production-bred flock, while LNM was considerably below this level until the last generation when a sharp rise of nearly roo gm. occurred bringing it back almost to the level of the I 944 production-bred flock. The LW lines show a more or less continuous decrease throughout the experiment. The $H N$ lines also steadily declined, although at a higher level. The difference of over $200 \mathrm{gm}$. between the HN and LW lines in the early generations was reduced to roughly half that amount by I95I.

The inbred lines generally tend to lie in the same descending order (HW, LN, HN, LW) as was observed for egg weight, being exactly so arranged in the last (I95I) generation. The crosses are in the expected order in all years except in 1950 , when $\mathrm{LN}$ and $\mathrm{HN}$ are reversed, and the LNM line was lower than the LW lines.

As in the case of egg weight, the crosses between lines selected for the same character in the same direction tend to lie above the corresponding inbreds. The crosses between the HW lines lie at a level (1899 gm.) approximately equal to the highest level attained by the inbred lines (1908 gm. in 1949).

Shank length.- Shank length in the inbred lines tended to follow the behaviour of egg weight and December body weight with only minor exceptions.

Six weeks body weight.-Body weight at six weeks of age was analysed only for generation 1949 through 1951. The behaviour of inbred lines and crosses in these generations indicated that the effects were very similar to those observed for November egg weight and December body weight.

\section{DISCUSSION}

General.-This experiment has shown that gains from selection for November egg number or November egg weight may be obtained in lines subjected to close inbreeding. Thus lines selected for the same character but in opposite directions become clearly differentiated from each other. Differentiation for egg weight was evident in the first generation but was not observable for egg number until the fourth generation.

The apparent early ineffectiveness of selection for egg number appears to be due to the variable effects of inbreeding degeneration occurring in the second and third generations. As this decline became arrested, the effects of selection became evident.

All lines except those selected for high weight (HWP and HWM) showed some depression of egg weight in the later stages of the experiment after computed inbreeding coefficients of approximately 30 per cent had been attained. Waters (I94I) observed a similar phenomenon. 
In general, crosses were arranged as expected with reference to egg weight on the basis of artificial selection pressures in the parental lines. Thus the descending order of crosses between similarly selected lines was HW, LN, HN and LW. The crosses with respect to egg number in r 95 I tended to follow the same behaviour. However, $\mathrm{HNP} \times \mathrm{HNM}$ was lower than $\mathrm{LNM} \times \mathrm{LNP}$, an exception not unexpected in view of the predominance of environmental variations (low heritability).

Also, crosses in which the LWM sire was involved were exceptionally high. Thus, $L W M \times H W M$ and $L W M \times L W P$, ranked first and third respectively among the 18 types of crosses performed. Unfortunately, no LWM females were available for crossing. The sire and dams from LWP behaved quite differently in crosses other than those with the LWM male. Hence, the unusual performance of the LWM male appears due to something peculiar to him rather than to a general characteristic of lines selected for low egg weight.

The $\mathrm{HN} \times \mathrm{HW}$ crosses clearly exceeded all other inbreds and crosses for egg mass. The $\mathrm{LN} \times \mathrm{LW}$ crosses were clearly lower for egg mass. This, however, is not a case of multiplicative gene action analogous to that in Powers' (1944) tomatoes because the majority of the effects at least are directly attributable to egg number. Thus, the crosses were in practically the same order for egg mass as for egg number.

Crosses between similarly selected lines tended to be superior to contemporary inbreds from the parental lines. This was true for the primary criterion of selection and also for those characters showing correlated response.

Correlated response.-Correlated response as a phenomenon characteristic of selection experiments has been treated in detail by Mather and Harrison (1949), Lerner (1950), and others. The present experiment adds further emphasis to this point. Computed correlations between the characters studied here have been presented in the section on the description of characters.

Correlated responses may not always be of a direct genetic nature. Thus, selection for egg number led to clear differentiation between the HN and LN lines with respect to egg weight, the LN lines having the higher egg weight (fig. I). However, selection for egg weight in the HW and LW lines was not effective in changing egg number. This situation is somewhat analogous to that reported by Lerner (1946) in which body size (or sexual maturity) appeared to limit the expression of genes for egg weight. In the present case, both characters are manifestations of metabolic efficiency, or the capacity of the bird for the production of total egg mass. Changes in egg number in the HN and LN lines may have resulted in the differentiation of these lines for egg weight largely through limitation in the HN lines of the amounts of material available for each egg. This interpretation is in agreement with Blyth (1952), namely that egg number and weight 
are correlated because the full genetic potential for egg size is not realised when the bird is laying at a high rate. The question here is whether the HN lines are laying at a sufficiently higher rate than the LN lines to account for the difference in egg weight. Egg number in the HW and LW lines would be expected to show some correlated response to selection for egg number. Small differences in egg number, however, would tend to be obscured by the larger magnitude of environmental variation.

Changes in November egg size were accompanied by corresponding changes in spring egg weight, six weeks body weight, December body weight, and shank length. These correlated changes appear to be of the magnitude expected on the basis of simple genetic correlations. Lerner (1950) gives the formula for estimating the expected changes in a correlated trait as :-

$$
\Delta \mathrm{G}_{\mathrm{B}}=r \mathrm{G}_{\mathrm{A}} \mathrm{G}_{\mathrm{B}} \frac{\sigma \mathrm{G}_{\mathrm{B}}}{\sigma \mathrm{G}_{\mathrm{A}}} \Delta \mathrm{G}_{\mathrm{A}}
$$

Where $\Delta \mathrm{G}_{\mathrm{A}}$ and $\Delta \mathrm{G}_{\mathrm{B}}$ are the genetic changes for the selected and correlated traits respectively (in this case, $\Delta \mathrm{G}$ was replaced by the difference between lines), $\sigma \mathrm{G}_{\mathrm{A}}$ and $\sigma \mathrm{G}_{\mathrm{B}}$ are the square roots of the respective genetic variances, and $r \mathrm{G}_{A} \mathrm{G}_{B}$ is the genetic correlation between the traits. The expected differences between the $\mathrm{HW}$ and LW lines for six weeks body weight and December body weight were calculated to be $72 *$ and $472 \dagger$ gm. respectively as compared to observed differences of approximately 69 and $514 \mathrm{gm}$. in I95I.

Cryptic gains from selection.-During the early stages of the experiment it was possible to apply strong selection pressures for high and low November egg number. In later generations, particularly during the disease outbreaks in 1949 and 1950, very little selection pressure for egg number was possible. However, differentiation between the $\mathrm{HN}$ and LN lines (the lines selected for egg weight being intermediate) was not apparent until the fourth generation (fig. 3). Hence gains from selection must have been made during the earlier stages but were obscured by the severe inbreeding degeneration occurring at different rates in the various lines. Such gains from selection have been described as cryptic by Lerner (1950).

Similarly, gains from selection were not always apparent in the inbred lines with respect to the size characters. However, crossing the lines allows the gains from selection to be fully expressed. Thus the unweighted means of reciprocal crosses between similarly selected lines were arranged in the descending order HW, LN, HN and LW for all characters of size in all three years such crosses were performed,

* The values used to obtain this figure $\left(\sigma \mathrm{G}_{\mathrm{A}}=1.2, \sigma \mathrm{G}_{\mathrm{B}}=13.7\right.$, and $r \mathrm{G}_{\mathrm{A}} \mathrm{G}_{\mathrm{B}}=0.42$ ) were computed by Dorothy Cruden Lowry from 1285 birds in the 1945, 1946, and 1948 hatched generation of the production-bred flock. The value for $\Delta \mathbf{G}_{\mathbf{A}}$ ( $15 \mathrm{gm}$.) was obtained from fig. 1 .

$\dagger$ The values used to obtain this figure $\left(\sigma G_{A}=2.4, G_{B}=80.4\right.$, and $\left.r_{G_{A}} G_{B}=0.942\right)$ were obtained from Lerner and Cruden (1951) and unpublished data from the same analysis. 
with the exception of six weeks and December body weights in the I950 generation.

Induced heterosis for egg size.- The release of cryptic responses from selection by the crossing of inbred lines will result in the phenomenon of heterosis. Egg weight of the HW crosses increased during the three years crosses were made. The HW inbreds, however, remained at the plateau reached the year before the first crosses were made. Hence it seems likely that the heterosis appearing in $195 \mathrm{I}$ was due to the fact that gains were being realised in the inbred lines in the later generations but were being nullified by the increasing effects of inbreeding. In the LN lines, in which there was only weak indirect selection for higher egg weight, the depressing effects of inbreeding were exhibited in the later generations. Crossing these lines returned egg weight to approximately the level shown by the inbred lines prior to the onset of the inbreeding depression. On the other hand, selection in the LW and HN lines was in the same direction as inbreeding depression. The crosses were approximately equal to or only slightly higher than the inbreds; and in one instance, $\mathrm{HN}$ with respect to spring egg weight in $195 \mathrm{I}$, the crosses were below the inbreds. It appears that gains from selection were expressed in the inbreds as well as in the crosses, these gains in some cases being augmented by an additional effect of inbreeding depression. It remains to be seen in future generations whether the crosses eventually will fall below the inbreds.

Dobzhansky (1948) explains heterosis induced by natural selection in wild populations of Drosophila pseudoobscura on the basis of coadaptation of the genic contents of chromosomes differentiated by inversions. The heterosis observed here in the HW lines has also arisen through the action of selection. However, it cannot be explained in the basis of co-adaptation because the lines have been isolated from each other. Heterosis in this case appears to be associated with metabolic efficiency. Egg weight depends on the availability of metabolic materials for maximum expression. As metabolic efficiency is decreased by inbreeding, egg weight in turn is depressed. The restoration of metabolic efficiency by crossing lines permits full realisation of the cryptic gains from selection for egg weight.

Optimal egg weight.-It is possible that the decline noted in the $\mathrm{HN}$ and LN lines during the latter stages of the experiment was due to natural selection rather than inbreeding. Artificial selection for higher egg weight in the production-bred flock, although not for the extreme deviates, nevertheless has resulted in the mean being higher than the optimal value for this flock (Lerner and Gunns, r 952). Relaxation of artificial selection in lines (HN and LN) derived from this flock should result in a return to the optimal level under the action of natural selection. The unweighted mean of these lines during the first three generations was relatively stable and approximately equal $\left(4^{8 \cdot 70}\right)$ to the 1944 production-bred flock $\left(4^{8 \cdot 60}\right)$. 
Thereafter, a consistent decline was observed which could be attributed to natural selection for an optimum at or below the level reached by these lines in 195I (45.75 gm.). Lerner (195I) and Lerner and Gunns (1952) computed the optimum to be $46 \cdot 29 \mathrm{gm}$. by fitting second degree polynomials to data obtained from a sample of 189 birds in the 1950 production-bred flock. The mean of the HN and LN inbreds in that year $(46 \cdot 0)$ is in close agreement. Under such a view, natural selection for optimal egg weight and artificial selection for high egg weight are in equil:brium in the HW lines whereas in the LW lines, gains to artificial selection are still being obtained although the pressure of natural selection is increasing (table 2).

On the other hand, if inbreeding were responsible, the crosses rather than the inbreds would be expected to yield the valid estimate of the optimum. The mean of the crosses in $195 \mathrm{I}$ was $48.20 \mathrm{gm}$., a value considerably above that of the inbreds. There are several reasons why the optimum computed by Lerner and Gunns may be too low with the 195 I crosses furnishing the best estimate.

I. The computed optimum was obtained from I950 records, one of the two years in which disease outbreaks depressed November egg weight. The mean of crosses between number lines in that year was $47.42 \mathrm{gm}$. which is roughly halfway between the $195 \mathrm{I}$ crosses and the computed optimum.

Furthermore, the disease outbreak in 1949 had a severe effect on egg number and also on egg weight particularly in certain lines (HWM and LWM). In general the crosses were more resistant to this disease than the production-bred flock (Lerner, Taylor and Beach, 1950). Although a similar study was not carried out for the disease epidemic in $195^{\circ}$ it is possible that the crosses were again more resistant. Consequently November egg weight may have been depressed more in the $195^{\circ}$ production-bred flock than in the crosses. Hence the disease may account for more than half of the difference.

2. The November egg weight used by Lerner and Gunns (1952) was based on the first five eggs laid in November whereas data in this experiment are based on all eggs laid during November. Since egg weight increases during this period, part of the difference may be accounted for by the difference in definition of the character.

3. The computed value was determined for fitness as measured by the number of offspring at the day-old stage, while the observed values refer to the number of offspring surviving to eight months of age.

4. Special hatchability tests similar to those of Lerner and Gunns (1952) were carried out in these lines in 195I by C. A. Gunns and Dorothy G. Lowry. The results obtained (unpublished) indicate that in the number lines, optimum egg size for hatchability was above the means of the respective lines. Optimum egg size was below mean egg size in the HW lines as expected. The data were too limited for conclusive results in the LW lines. 
The discrepancy between the computed and observed (from crosses) optimums in no way invalidates the conclusions reached by Lerner (I95I) that the optimal value of egg weight with respect to fitness lies below the mean of the production-bred flock. In fact, these data strengthen that view, the optimum estimated from I 95 I crosses being $3 \cdot 0 \mathrm{gm}$. below the mean of the production-bred flock $\left(5^{\mathrm{I}} \cdot 2 \mathrm{gm}\right.$.)

Balance for fitness.-Düzgünes (1950) noted that there was selective elimination of the relatively more homozygous individuals in the lines studied here, suggesting the presence of a balance mechanism for fitness. Shultz and Briles (1953), by using genes involved in the production of cellular antigens as markers, demonstrated the effectiveness of selective forces in maintaining balanced polymorphism in these lines, in four additional inbred lines, and in the relatively noninbred production-bred flock. The results presented here are further evidence for the existence of a balance mechanism.

The responses to direct selection for high and low November egg weight had virtually ceased by the third generation. No noticeable decrease in the genetic variance from inbreeding was observed (table 3 ). It was found, however, that natural selection was acting in favour of an intermediate egg weight. Thus in the HW lines, dams with smaller egg size reproduced themselves better whereas in the LW lines the dams with higher egg weight reproduced themselves better (table 2). These differences were greater in the generation during which the lines were plateaued than during the earlier generations when gains were being obtained.

Hence, the presence of an optimum egg weight appears to be due to an association of egg weight with the balance mechanism for fitness. The greater the deviation of egg weight of the population from the adaptive peak, the stronger are the forces of natural selection which tend to restore balance for fitness. This negative correlation between fitness and the deviation of a selected character from the optimum has been previously demonstrated in a line of chickens selected for long shanks by Lerner, and Dempster (I95I), much as expected on the basis of Mather's (194I) theory of polygenic balance.

The behaviour of November egg number also is suggestive of a balance mechanism. This trait was characterized by severe inbreeding degeneration (fig. 3) in the second and third generations in which mean levels of inbreeding of $0 \cdot 16$ and 0.29 were attained. No further general decline in egg number occurred although the computed inbreeding coefficient increased to over 0.50 in the next four generations. Artificial selection for high egg number was not sufficient to prevent the severe decline although it did result in a higher equilibrium level in the HN lines than in the other lines.

Unless there is a threshold level of homozygosity beyond which no further detrimental effects occur, an unlikely possibility, one must assume that some force becomes effective in arresting the decline. The only possible force appears to be natural selection. Thus con- 
tinuous inbreeding pressure acting towards homozygosity with the resulting disruption of balance for fitness is opposed by strong natural selection in favour of the heterozygotes.

Crossing lines will tend to restore balance disrupted by inbreeding. If a character depends to large extent on a balance mechanism, its expression in crosses will depend on the degree to which such balance is restored. It might be expected that crossing two inbred lines in which selection has acted towards greater genetic differentiation will tend to restore balance to a greater extent than crossing two lines in which selection has acted towards genetic similarity. This may be the explanation for the superiority of November egg number of the crosses between differently selected lines over crosses between similarly selected lines. This same situation also was noted for egg weight but only to a slight extent. The reverse is true, however, for December body size.

\section{CONCLUSIONS AND SUMMARY}

On the basis of the data obtained, some inferences as to the nature of the genetic system operating in this material can be made. The pertinent observations are outlined below.

I. A reduction in reproductive fitness in the eight lines due to inbreeding has occurred (Düzgünes, 1950). This effect led to a decline in the amount of selection pressure that could be practiced. Disease epidemics in 1949 and $195^{\circ}$ ( $5^{\text {th }}$ and 6th generations), further reduced the effectiveness of artificial selection.

2. Close consanguineous mating caused a decline in November egg number in the second and third generations, no further decline occurring in the next four generations even though the degree of inbreeding greatly increased.

3. A decline in November egg weight began coincident with the cessation of the degeneration in egg number and continued throughout the duration of the experiment.

4. Differentiation between lines selected in opposite directions for egg number did not become apparent until the fourth generation when inbreeding degeneration ceased, although the most effective selection pressures had been applied in the previous generations.

5. Responses to selection for egg weight were immediately apparent. These visible responses ceased by the fourth generation.

6 . Within lines, dams whose egg weight was closer to the optimum tended to reproduce themselves better (table 2).

7. The behaviour of egg mass (weight multiplied by number) was almost identical to that of egg number.

8. Differentiation with respect to egg number between the lines selected for high number (HN) and low number (LN) was accompanied by a correlated differentiation of these lines with respect to egg weight. The reverse was not noticeable in the lines selected for high and low egg weight (HW and LW). 
9. Correlated response of spring egg weight, six weeks body weight, December body weight, and shank length with November egg weight was noted. Changes in body weight were of the magnitude expected on the basis of simple genetic correlations between characters.

10. The ranking with respect to mean egg number of crosses between lines selected for the same character in the same direction was essentially that expected on the basis of selection for egg number. Crosses were generally superior to the contemporary inbreds, but did not exceed the production-bred flock from which the inbred lines were derived.

II. The means of crosses with respect to egg weight fell in the order of magnitude expected on the basis of additive gains from selection. These crosses were superior to the mid-values of the contemporary inbreds from the parental lines.

12. Crosses between lines selected differently tended to be superior to crosses between similarly selected lines. This was especially true for egg number and to some extent for egg weight but not for December body size.

It is apparent that the genotype is not simply a collection of independently acting genes. Rather it is an integrated complex which has arisen during the course of evolution under natural selection acting on an essentially heterozygous system. The characters studied here are but more or less interrelated manifestations of the general underlying physiological organisation and should be considered in part as indicators of the condition of that organisation. Thus egg number and egg weight are correlated manifestations of metabolic efficiency. The negative correlation between them exists only at higher rates of production where the ability of the bird to produce sufficient metabolic products for maximum expression of both characters is exceeded (Blyth, 1952). The relationship, however, is not adequately expressed simply as the total egg mass produced as shown by point 7 above. Similarly, the size characters studied can be considered to be manifestations of a basic physiological condition as shown by the correlated responses to changes in egg weight.

Interpretation of these results requires a consideration of three forces-natural selection, artificial selection, and inbreeding. The action of these forces produces changes in the genetic composition of a population until an equilibrium between them is reached. This results in an apparent stability of the mean of the population. Further observable changes are then dependent either on an alteration of the relative pressures of these forces or on fundamental changes in the genetic structure. However, the underlying genetic basis for the equilibrium may be changing even though such changes are not reflected on the phenotypic level.

These data furnish three illustrations of the establishment of an equilibrium. First, the rapid decline in November egg number to a lower stable level appears best explained on the basis that inbreeding 
disrupts the heterozygous balanced genetic system for fitness. The increase in homozygosity is opposed by natural selection and an equilibrium is reached as a result. That artificial selection has also played a part is clearly shown by the fact that the lines selected for high and low number plateaued at a higher and lower level respectively than the inbred-control lines which were not selected for egg number. These gains were in part cryptic during early generations finally becoming apparent when further inbreeding degeneration ceased.

The plateau shown by November egg weight in the HW lines furnishes the second example. Part of the cessation of gains from selection for high egg weight was due to the opposition of natural selection, as demonstrated here by the fact that dams with lower egg weight reproduced themselves better. It appears, however, that some gains were being realised during the plateau period but were cryptic owing to a counterbalancing depressing effect of inbreeding. Removal of the depressing effect of inbreeding by crossing allowed the expression of the cryptic gains from selection resulting in the heterotic behaviour of the HW crosses. The HN and LN lines (in which the primary selective force was natural selection towards the optimum) exhibited inbreeding degeneration. On crossing these lines, egg weight was restored to the optimal level.

The third example is the behaviour of egg weight in the LW lines. The short plateau around the third generation apparently represents an equilibrium between artificial and natural selection. Thus dams with higher weight reproduced themselves better (table 2). In later generations despite an increase in the pressure of natural selection for higher egg weight, further decreases were obtained presumably by the joint action of artificial selection and inbreeding. Crossing the lines restored egg weight to the level of gains from selection, in this case slightly below the plateau level of the third and fourth generations.

Thus natural selection tends to maintain the heterozygous system characteristic of the adaptive peak established during the course of evolution. Artificial selection and inbreeding as encountered in the improvement of domestic animals will tend to disrupt this balanced genetic system with a decrease in the metabolic efficiency and reproductive fitness characteristic of that adaptive peak. It may be expected then, that computed inbreeding coefficients will overestimate the actual amount of homozygosity achieved as indicated previously by Düzgünes (1950) and Shultz and Briles (1953) for this material, and by Mather (1950) in a more generalised fashion. Furthermore, genetic gains as a result of artificial selection for a character (e.g. egg weight) dependent for its maximum expression on an efficient physiological system may not be apparent on the phenotypic level. Restoration of the heterozygous system by crossing allows the expression of these cryptic gains.

Acknowledgment.-The author wishes to express his appreciation to Dr I. Michael Lerner for his many contributions to this work. 


\section{REFERENCES}

Ashton, T. 1946. The use of heterosis in the production of agricultural and horticultural crops. Cambridge : Imp. Bur. Plant Breed. Genet.

BELl, A. E., MOORE, C. H., BOHREN, B. B., AND WARREN, D. C. 1952. Systems of breeding designed to utilise heterosis in the domestic fowl. Poultry Sci., 31, I I-22.

BLYTH, J. s. s. 1952. The correlation between egg number and egg weight in the fowl : an investigation of its inconstancy. Poultry Sci., 3I, 254-268.

DICKERSON, G. E., LUSH, J. L., AND GULBERTSON, G. C. 1946. Hybrid vigor in single crosses between inbred lines of Poland China swine. 7. Animal Sci., 5, 16-24.

DoBzhansky, T. 1947. Adaptive changes induced by natural selection in wild poulations of Drosophila. Evolution, $I, \mathrm{I}-26$.

DOBZHANSKY, T. 1948. Observations and experiments on natural selection in Drosophila. Proc. 8th Int. Cong. Genctics, Abstr. Book, pp. 33-34.

DOBZHANSKY, T. 1950. Origin of heterosis through natural selection in populations of Drosophila pseudoobscura. Genetics, 35, 288-302.

DUBinin, N. P. 1948. (Experimental investigation of the integration of hereditary systems in the processes of evolution of populations.) Zhurn. Obshch. Biol., 9, 203-244. (In Russian.)

DÜZGüNEs, o. 1950. The effect of inbreeding on reproductive fitness of S.C.W. Leghorns. Poultry Sci., 29, 227-235.

Jull, M. A. 1952. Poultry Brecding (3rd edition). N.Y. : John Wiley and Sons.

LERNER, I. M. 1946. The effect of selection for shank length on sexual maturity and early egg weight in Single Comb White Leghorn pullets. Poultry Sci., 25, 204-209.

Lerner, I. M. 1950. Population Genetics and Animal Improvement. Cambridge.

LERNER, I. M. I951. Natural selection and egg size in poultry. Amer. Nat., 85, $365-372$.

LERNER, I. M., AND CRUDEN, D. I95I. The heritability of egg weight : the advantages of mass selection and early measurements. Poultry Sci., 30, 34-41.

LERNER, I. M., GRUDEN, D., AND TAYLOR, L. W. 1949. The relative breeding worth of full sisters. Poultry Sci., 28, 903-913.

LERNER, I. M., AND DEMPSTER, E. R. I95I. Attenuation of genetic progress under continued selection in poultry. Heredity, .5, 75-94.

LERNER, I. M., AND GUNNS, C. A. 1952. Egg size and reproductive fitness. Poultry Sci., 3I, 537-544.

LERNER, 1. M., AND HAZEL, L. N. I 947 . Population genetics of a poultry flock under artificial selection. Genetics, 32, 325-339.

LERNER, I. M., TAYLOR, L. W., AND BEACH, J. R. 1950. Evidence for genetic variation in resistance to a respiratory infection in chickens. Poultry Sci., 29, 862-869.

MATHER, K. I94I. Variation and selection of polygenic characters. 7. Genet., 4I, I59-193.

MATHER, K. I950. The progress and prospect of biometrical genetics. In Genetics in the 2oth Century, ed. Dunn. N.Y. : Macmillan.

MATHER, K., AND haRrison, B. J. 1949. The manifold effect of selection. Heredity, $3,1-52$ and $131-162$.

POWERS, L. 1944. An expansion of Jones' theory for the explanation of heterosis. Amer. Nat., 78, 275-280.

ShULTZ, F. T., AND BRILES, W. E. 1953. The adaptive value of blood group genes in chickens. Genetics, 38, 34-50.

SPRAGUe, G. F. 1946. The experimental basis for hybrid maize. Biol. Rev., 2I, $101-120$.

taylor, L. W., And lekner, I. M. 1938. Breeding for egg production. Cal. Agr. Exp. Sta. Bull., no. 626 .

WARREN, D. C. I 950 . Techniques of hybridisation of poultry. Poultry Sci., 29, 59-63. WATERS, N. F. I $94^{1}$. Genetic aspects of egg weight observed during inbreeding experiments. Poultry Sci., 20, 14-27. 